\title{
Determinants of the intention to use condoms in a sample of French adolescents
}

Potard $\mathrm{C}^{1,2}$, Courtois $\mathrm{R}^{2,3}$, Le Samedy $\mathrm{M}^{2}$, Mestre $\mathrm{B}^{4}$, Barakat $\mathrm{MJ}^{4}$, Réveillère $\mathrm{C}^{2}$

${ }^{1}$ University of Reims, Department of Psychology, EA4296, Reims, France,

${ }^{2}$ University François Rabelais of Tours, Department of Psychology, EA 2114 'Psychology of the ages of life', Tours, France,

${ }^{3}$ Psychiatric University Clinic, University Hospital of Tours (CHRU), Tours, France,

${ }^{4}$ Department of Health Promotion, School Inspectorate of Indre-et-Loire, Tours, France

Short title: Determinants of condom use intentions of French students

Key words: Sexual attitudes; Condoms; Adolescent psychology; Theory of Planned Behaviour; Sex education

Correspondence: Dr. Catherine Potard, Université Reims Champagne Ardenne, Département de Psychologie, EA 4296, 57 rue Pierre Taittinger, 51100 REIMS, France.

Tel : +33 (0)3.26.91.80.62. . E-mail: catherine.potard@univ-reims.fr 


\section{ABSTRACT}

Objective. To identify the determinants of the intention to use and actual use of condoms in a sample of French adolescents based on Ajzen's Theory of Planned Behaviour.

Method. Two-hundred-and-thirty French secondary-school students (mean age: 17.68 years; $\mathrm{SD}=1.08$ ) completed a questionnaire about condom use intention.

Results. 'Perceived behavioural control', 'individual attitudes', 'subjective socio-cultural norms' and 'subjective norms of close friends and relatives' are the main factors explaining $33 \%$ of variance of condom use intention. For girls, intention is essentially associated with perceived control, subjective norms ('close friends and relatives', and then, 'socio-cultural norms') and individual attitudes, whereas for boys, it is more closely linked to individual attitudes and to subjective socio-cultural norms. The best predictors of the intention to use a condom are perceived control and individual attitudes for girls while, for boys, individual attitudes come before perceived control.

Conclusion. In order to design effective programmes for prevention of sexually transmitted infections, the determinants of the intention to use condoms must be considered. 


\section{INTRODUCTION}

The risk of contracting a sexually transmitted infection (STI) is one of the immediate and major threats that hang over the health and well-being of adolescents. It is during adolescence that the first decisions relative to sexual activity tend to be taken. In France, nearly $54 \%$ of young men and $46 \%$ of young women aged 15 to 19 have had sexual intercourse at least once ${ }^{1}$. With this early initiation of sexual activity, adolescents face risks such as undesired pregnancies and STIs ${ }^{2}$. In France over the last ten years, just over 10,000 pregnancies have been reported per year for minors, and $10 \%$ of French adolescents have Chlamydia or gonorrhoea ${ }^{4,5}$. This finding is particularly worrying as a history of STI is known to be a strong predictor of future diagnoses of STIs ${ }^{6}$. HIV and AIDS do affect adolescents: $25 \%$ of HIV-positive people worldwide are aged under $25^{5,6}$. The most efficient means of preventing STIs and HIV is still the systematic use of condoms. While $88 \%$ of young French people who have had sex claim they used a condom during their first sexual encounter, only $80 \%$ of boys and $53 \%$ of girls said they used one during their most recent sexual experience ${ }^{7}$. This lack of systematic use of condoms is not specific to France ${ }^{8}$.

It is important to understand the psychological determinants underpinning regular condom use by adolescents. Adolescence is a period when the influence of peers and the social environment is strong and contributes significantly to the attitudes and sexual behaviour of young people. It thus appears relevant to apply a socio-cognitive model, namely the Theory of Planned Behaviour (TPB) ${ }^{9,10}$, which aims to identify the variables predicting 'behaviour' or 'behavioural intention'. This model focuses on behavioural intention, identified by a set of beliefs: 'perceived behavioural control', 'attitudes toward the behaviour' and 'subjective norms'. 'Perceived behavioural control' evaluates the person's perceived ability to control his or her own behaviour by identifying perceived barriers or enablers, either 
internal ("I'm sufficiently sure of myself to use a condom.") or external ("It is difficult to buy condoms."). According to the TPB, 'perceived behavioural control' may also have a direct effect on the 'actual behaviour' (irrespective of intention). 'Attitudes toward the behaviour' assesses whether the person has a favourable or unfavourable view of the behaviour in question by examining his or her beliefs about the consequences of the behaviour ("not using a condom results in a risk of HIV infection") and the importance given by the individual to these consequences ("It's not serious to have HIV."). 'Subjective norms' refers to the social pressure perceived by the person to perform the behaviour or not. It is identified by the opinions of key people (family, peers) ("My parents think I should use a condom when I have sex.") and the desire to comply with these opinions or not ("I shall not comply with what my parents want me to do."). According to the TPB, these three elements determine the 'intention' which, in turn, will determine the 'behaviour'. A meta-analysis has demonstrated the relevance of this type of model for explaining behaviour ${ }^{11}$.

Note to the Publisher: Insert Figure 1 about here

A number of studies on the prevention of risky sexual behaviour have used the TPB 12,13. The results are interesting and promising, although they do not always converge. They highlight the links between the intention to use and the actual use of condoms (the 'actual behaviour') ${ }^{12}$ and the importance of individual attitudes in predicting intention ${ }^{14}$. However, they also reveal the importance of subjective norms whose effects could over-ride those of attitudes in predicting condom use ${ }^{15,16}$. The role of 'perceived behavioural control' with regard to the 'intention' to use condoms is subject to the same controversy. For example, Wilson et al. ${ }^{17}$ concluded that it only explains a small percentage of the variance and only has predictive value for men, while Godin et al. ${ }^{18}$ found stronger links between perceived control and intention than between intention and attitudes or subjective norms. 
The aim of this study is to test the application of Ajzen's Theory of Planned Behaviour ${ }^{9,10}$ to risky sexual behaviour. We examined the factors predicting the intention to use a condom among a sample of French adolescents, and looked at the effect of gender.

\section{METHODS}

\section{Subjects}

Participants were 230 French high-school students $\left(10^{\text {th }}-12^{\text {th }}\right.$ grade $)$ in five different schools in the département of Indre-et-Loire (France). This département is in the centre of France and has a population of just under 600,000 inhabitants. The participants attended general or technical schools (46\%), vocational schools (26\%), and agricultural schools (28\%). The sample comprised $74 \%$ girls $(n=169)$ and $18 \%$ boys $(n=42)(19$ students, i.e. $8 \%$, did not indicate their gender). Mean age was 17.68 years $(\mathrm{SD}=1.08)$. The mean age of the girls was 17.61 years $(\mathrm{SD}=1.07)$ and that of the boys was 17.84 years $(\mathrm{SD}=0.85)$, with no significant difference between boys and girls.

\section{Material}

The material was largely inspired by a study by Gagné and Godin ${ }^{19}$ who proposed a methodology for constructing a questionnaire of behavioural intention based on sociocognitive theory (notably the TPB) and provided examples of items for the intention to use condoms. It comprises 21 self-administered questions about subjective norms, attitudes, behaviour, perceived control and intention to use condoms, scored on a 5-point Likert scale. For example, one item for subjective norms is: "It would be appropriate for a person of my gender to use a condom during every sexual encounter." (on a scale ranging from 1 "totally agree" to 5 "totally disagree"); questions about attitude include: "Using a condom would be easy/ difficult for me" (on a scale ranging from 1 "very easy" to 5 "very difficult"). One item 
measuring perceived control is: "I feel capable of using a condom during every sexual encounter/every time I have sex" (on a scale ranging from 1 "totally agree" to 5 "totally disagree"). The item regarding intention to use condoms was: "I intend to use a condom every time I have sex with a new partner in the next three months". A "new partner" was any person with whom the teenager had sexual intercourse for the first time. The answer was given on a 5-point scale, ranging from 'unlikely' to 'likely'. The item regarding actual condom use was: "How many times have you used a condom in the last three months when having sex with a new partner?" Answers were quantified as follows: zero, one out of four times, two out of four times, three out of four times, every time. Participants could also tick a box if they had not had any sexual encounter.

\section{Procedure}

After obtaining the permission of the school administrators, the parents of students under the age of 18 , and the adolescents themselves, the questionnaires were handed out in class, either by the school nurse or the head teacher. Classes were selected at random by the school administrators. All the data were collected using the self-administered questionnaires. The purpose of the study and the questionnaire procedure were explained, emphasising the confidentiality and anonymity of the data. Clear and precise instructions were given and the importance of giving honest answers was stressed. The entire procedure was carried out in accordance with the ethical principles applicable to research on sexual behaviour ${ }^{20,21}$ and with the agreement of the Committee for Health Education and Citizenship of each institution. There was a $100 \%$ response rate among the students present as the study was carried out in class. However, some questionnaires were only partially completed.

\section{Data analysis}


We used exploratory factor analysis techniques to identify the determinants of intention and behaviour predicted by the TPB model, and we measured the internal consistency of the factors using Cronbach's Alpha coefficient (a score of $>0.70$ suggests that the internal consistency is good). We used variance analysis (ANOVA) for comparison between groups (e.g., gender) and Spearman's correlations to evaluate the relationship between determinants. The TPB model was tested using multiple regression analyses and Structural Equation Modelling (SEM). An alpha level of less than 5\% was considered statistically significant. Statistical analyses were performed with SPSS ${ }^{\circledR}$ and AMOS $^{\circledR}$.

\section{RESULTS}

\section{Descriptive results: sexual relationship and condom use}

Of the adolescents assessed, $38 \%(n=85)$ stated that they had not had a sexual (coital) relationship during the previous three months, or had never had a sexual relationship (virgin). Seven adolescents did not answer this question, which could bring the percentage of this group to $40 \%(n=92)$. For the $62 \%$ of adolescents $(n=139)$ who had had sexual intercourse during the previous three months, $22 \%(\mathrm{n}=31)$ stated that they had never used a condom, $9 \%$ $(n=12)$ that they had only used a condom one out of four times, 5\% ( $n=7)$ one out of two times, and $14 \%(n=19)$ three out of four times, while $50 \%(n=70)$ stated that they had used a condom on the occasion of every sexual encounter.

With regard to the intention to use condoms in future sexual encounters, 59\% $(n=133)$ of the adolescents stated that their condom use was "absolutely sure", 24\% $(n=55)$ that it was "fairly probable", $5 \%(\mathrm{n}=11)$ that it was "not probable or not very probable", and for $12 \%(\mathrm{n}=$ 26) there was an equal probability that they would and would not use a condom.

\section{Exploratory factor analysis to identify the TPB determinants of intention and behaviour}


First, we carried out a principal components factor analysis using Varimax rotation ${ }^{22}$ on the data obtained from the answers to 19 out of the 21 items assessed (the two questions regarding intention and actual condom use were treated separately). The analysis identified four factors explaining $55 \%$ of total variance (Table 1). The first (factor I), 'subjective sociocultural norms regarding condom use' concerned how the adolescents conformed to their socio-cultural environment with regard to condom use (in terms of culture, age and gender). This factor had an intrinsic value of 5.7 and explained just over $30 \%$ of the total variance. . The second factor (factor II), 'individual attitudes to condom use', concerned personal opinions about condom use. It had an intrinsic value of 1.8 and explained just over $9 \%$ of the total variance. The third factor (factor III), 'subjective norms of close friends and relatives', concerned the recommendations and opinions of close friends and relations regarding condom use. It had an intrinsic value of 1.7 and explained nearly $9 \%$ of total variance. Finally, the fourth factor (factor IV), 'perceived control', concerned the perceived ability to implement the behaviour and explained just over $6 \%$ of variance, with an intrinsic value of 1.2. The Cronbach alphas for these four factors were $0.67,0.73,0.85$ and 0.77 , respectively. As mentioned above, Cronbach alphas are acceptable when they are close to or above 0.70 .

This factor analysis thus reveals the three main determinants identified by the TPB: 'perceived behavioural control', 'attitudes toward the behaviour' and 'subjective norms'. Each of these categories can refer to different factors, separately or combined, depending on the respondents and questionnaire items. In our study, 'subjective norms' had two forms, 'subjective socio-cultural norms' and 'subjective norms of close friends and relatives'. It can be explained by the internalisation of social norms and by strong peer-identification during adolescence. 'Subjective socio-cultural norms' describes the set of normative beliefs of adolescents - what is and is not done - in relation to gender, age or culture, in other words, the norms of society as a whole, for example: "It would be appropriate for a person of my gender 
to use a condom during every sexual encounter". 'Subjective norms of close friends and relatives' concerns normative beliefs based on the perception of the attitudes and behaviour of peers and family. These are proximal normative beliefs. For example: "The people who are most important to me think that I should use a condom."

Note to the Publisher: Insert Table 1 about here

\section{TPB model for condom use intention (in general and by gender)}

Before testing the TPB model, we examined whether there were any gender differences for the new variables identified by the factor analysis. We observed a gender difference for 'subjective norms of close friends and relatives' $(p<0.01)$ and 'intention to use a condom' $(p<0.05)$, which were both higher for the girls. To test the TPB model, we first carried out a correlational analysis (Table 2) of 'subjective norms' (in relation to 'socio-cultural norms' and 'close friends and relatives'), 'individual attitudes', 'perceived control', 'intention to use a condom', and 'condom use'. 'Intention to use a condom' and 'condom use' were also linked $(0.36, p<0.001)$

Next, we carried out a step-by-step multiple regression analysis to determine the relative weight of norms, attitudes and perceived control on the 'intention to use a condom'. They explained $33 \%$ of the variance $(p<0.001)$, with first 'perceived control' which made up the first step and explained $15 \%$ of the variance, then 'individual attitudes' $9 \%$, and finally 'subjective socio-cultural norms' and 'subjective norms of close friends and relatives' bringing about $5 \%$ and $4 \%$ of additional variance, respectively $(p<0.001)$. We carried out the same procedure for 'condom use', including 'intention' in the explanatory variables. They explained $33 \%$ of the variance $(p<0.001)$, with 'individual attitudes' explaining just under 
$19 \%$, 'perceived control' approximately $11 \%(p<0.001)$, and finally 'subjective norms of close friends and relatives' accounting for $4 \%$ of additional variance $(p<0.01)$. As mentioned above, when analysing condom use, only the data from students who had had sex were included ( $\mathrm{n}=139$ instead of $\mathrm{n}=230)$.

Note to the Publisher: Insert Tables 2 and 3 about here

All these results were re-analysed according to gender (Table 3). Notable findings were that there were stronger relationships between 'intention to use a condom' and the 'subjective norms of close friends and relatives' and 'perceived control' for girls than for boys, whereas the relationship between 'intention', 'individual attitudes' and 'subjective socio-cultural norms' was stronger for boys than for girls. Similarly, for 'condom use' there was a stronger relationship with 'perceived control' for girls and with 'individual attitudes' for boys. The relationship between 'intention to use a condom' and 'condom use' was $0.31(p<.005)$ for girls and $0.45(p<0.05)$ for boys.

For girls, the step-by-step multiple regression analysis of 'intention to use a condom' explained $35 \%$ of the variance $(p<0.001)$, with 'perceived control' explaining 20\%, 'individual attitudes' $6 \%$, 'subjective socio-cultural norms' close to $6 \%(p<0.001)$, and 'norms of close friends and relatives' 3\% ( $p<0.01)$. For boys, the explained variance was 39\% $(p<0.001)$, with 'individual attitudes' explaining nearly $27 \%(p<0.001)$ and 'perceived control' $10 \%(p<0.05)$. The multiple regression analysis for 'condom use' identified $32 \%$ of explained variance in girls $(p<0.001)$, with 'individual attitudes' explaining $20 \%$ and 'perceived control' $10 \%(p<0.001)$. For boys, $58 \%$ of the variance was explained $(p<0.001)$, with 'individual attitudes' explaining 41\% $(p<0.001)$ and 'perceived control' $12 \%(p<0.05)$. 
Finally, we checked the conformity of our data with the theoretical TPB model by structural equation modelling $(\mathrm{SEM})^{23}$. SEM provides a parsimonious and logical explanation of observed relationships for the measured variables. Variants were tested on the basis of previous correlation or multiple regression results. The model combined the four dimensions of the factor analysis and 'intention' and 'condom use'. Relationships are shown in figure 2 $\left(\chi^{2}=331.5, \mathrm{df}[\right.$ degrees of freedom $]=145 ; \chi^{2}[\mathrm{CMIN}] / \mathrm{df}=2.29 ; \mathrm{CFI}$ [Comparative fit index $]$ $=0.86$, and RMSEA [Root Mean Square Error of Approximation] $=0.07$ [0.6 to 0.8]). The values of these indices are acceptable, with a $\chi^{2} / \mathrm{df}$ ratio close to 2 , CFI close to 0.90 , and RMSEA $<0.08$. It should be noted that the model does not include the relationship between 'intention' and 'condom use' (not significant here). The model was also tested without 'condom use' $(\mathrm{n}=230)$ because we did not find any link between intention and actual behaviour in our previous results. The indices are acceptable $\left(\chi^{2}=318.3, \mathrm{df}=129 ; \mathrm{CMIN} / \mathrm{df}=\right.$ 2.47; $\mathrm{CFI}=0.86$, and $\mathrm{RMSEA}=0.08$ ).

Note to the Publisher: Insert Figure 2 about here

The whole model was also tested for girls only $(n=102)$, with similar indices $\left(\chi^{2}=\right.$ 278.2, $\mathrm{df}=145 ; \mathrm{CMIN} / \mathrm{df}=1.92 ; \mathrm{CFI}=0.86$, and RMSEA $=0.07)$. A few slight modifications were made to the structural equation: the relationship between 'individual attitudes' and 'condom use' 0.39 ; the relationships between 'perceived control' and 'intention to use a condom' 0.65 , and 'condom use' $0.22, p<0.001$. It was not possible to test the model for boys for 'condom use', because of their low number, which was less than the number of parameters to be estimated ${ }^{24}$.

\section{DISCUSSION}


In this study of adolescents, the 'intention' to use a condom during every sexual encounter was essentially explained by 'perceived control' and 'individual attitudes', and to a lesser extent by 'subjective norms of close friends and relatives' and 'socio-cultural norms'. Our results thus indicate that these four determinants are important in adolescents' intention to use a condom. For example, adolescents with a positive attitude to condoms and who say that they feel able to use them report a greater intention to use condoms than their peers with a less positive attitude. This behavioural intention is usually strongly linked to actual behaviour ('condom use'). However, in this study, the correlation between intention and actual behaviour was only 0.36 , which is lower than that reported by Gredig et al. ${ }^{25}$ or in the metaanalysis by Albarracin et al. ${ }^{12}$. Thus our chosen structural equation model further reduces this relationship, which is non-significant when all the variables are included. It should be kept in mind that while we chose the best adapted model, this does not necessarily mean that it is 'true' or the only one ${ }^{24}$, but only that it is the one that reveals best the relationships between the variables examined in this study. The weaker relationship could be explained by the fact that women have less control over the use of condoms, as indicated by the difference between girls and boys in the relationship between 'intention to use condoms' and 'condom use' $(0.31$ for girls and 0.45 for boys). The TPB model, widely used in the study of health behaviour, postulates a close link between intention and behaviour. In our study, no significant relationship between condom use intention and behaviour was found. This can be explained by the fact that condom use does not just involve one person (like smoking, drinking, eating, etc.), but involves interaction and negotiation with another individual. Condom use is closely linked to the environmental context and relationships, and as such, the intention is not necessarily transformed into action.

The finding that 'perceived control' (self-efficacy, 'I can do it if I want to') contributes to 'intention' is important, because it highlights the impact of personal judgment on the ability 
or inability to use a condom and on the intention to have protected sex. This factor reflects an individual's personal resources, skills, and the effective possibility of performing the behaviour. Our results confirm those of previous studies showing that there is a relationship between perceived control and the intention to use a condom ${ }^{12,18,25,26}$. With regard to use (actual behaviour), this study also shows that perceived control is an essential factor. We also found that the overall perception and ability to overcome obstacles specifically linked to 'condom use' seems to be another essential determinant of the intention to use them. The more a young woman feels at ease with using condoms (self-efficacy), the more she is likely to use one during her sexual encounters. This analysis applies mainly to girls, because the 'perceived control' variable is not significantly associated with 'intention to use a condom' for boys. These results seem to corroborate those of Muñoz-Silva et al. ${ }^{27}$. It thus seems appropriate to help adolescents develop this sense of control by teaching them the necessary skills (always carrying condoms, initiating discussions about condoms in non-sexual situations, learning to use a condom, etc.).

'Individual attitudes' (favourable or unfavourable attitudes toward the use of condoms) is the second psychosocial factor found in this study to have a significant impact on the intention to use a condom. Adolescents' personal ideas and opinions regarding condoms directly influence their intention to have protected sex or not. These results are in line with those of Craig et al. ${ }^{28}$ for both boys and girls. 'Individual attitudes' to condoms also influence behaviour. This suggests that personal attitudes can automatically activate condom use behaviour $^{12,26}$, and teaching adolescents about the advantages of condom use could influence and encourage their decision to use them. One strategy for changing attitudes toward condom use is for example to convince young people that using condoms will not reduce their (and their partner's) sexual pleasure. However, this strategy may encounter resistance especially 
when personal beliefs are based on experience (as in the previous example) and not on external information (sexual health campaigns).

The role of 'subjective norms' (perception of the opinions of people who are important to the individual about condom use) in predicting the intention to use a condom highlighted in this study has also been regularly reported by researchers in condom use behaviour ${ }^{12,16}$. However, in contrast to the results of Bosompra ${ }^{15}$, we found that 'subjective norms' predicted the intention to use a condom less than 'individual attitudes'. However, our result is in line with several published studies in the field of health that have maintained that subjective norms' is a fairly weak determinant of intention to use a condom ${ }^{11,12}$. For girls, 'subjective socio-cultural norms' and 'close friends and relatives' have an impact on 'intention to use a condom', but not on actual condom use ('behaviour'). While 'subjective norms of close friends and relatives' have an effect on the intentions of adolescent girls to use condoms, it has none on those of adolescent boys. The desire for social conformity is thus specific to girls who seem to be sensitive to the norms of their social group. 'Subjective socio-cultural norms' also influences the intentions of boys to use condoms; this suggests that boys are motivated to conform more to the norms of society than to those of their social group. These results show the importance of developing a gender-based model. Girls are more sensitive to the attitudes of significant people or groups to condom use, while boys are more influenced by a desire to conform to the group. Health-care professionals should therefore help each young person identify significant people and consider what they think about condom use, as a prerequisite for any intervention promoting condom use. The importance of the group suggests that condom use programmes should be based on learning by imitation and experience sharing.

\section{Limitations}


The main limitation of this study is the fundamental methodological problem inherent in all cross-sectional studies, namely the difficulty of determining the causes underlying the associations and influences found among the variables. There was also only one item measuring the intention to use a condom, and one for measuring actual behaviour. It would have been better to choose several items for each case and to obtain a score after factor analysis. This would have improved the fit of these variables to the sample. Other potential limitations include confidence in the self-evaluation of sexual activity (social desirability). Furthermore, due to the specificity and size of the sample and the over-representation of girls, the results of this study should be interpreted with caution; they cannot be generalised beyond adolescents attending school. Investigators addressing this issue in the future should bear these methodological limitations in mind in order to define more precisely the relationships between the determinants and the TPB, the intention and actual use of condoms. Other psychological variables, such as self-esteem or personality should also be considered, with a view to assess their possible mediating effects in the TPB model for intention to use a condom and actual use. In this study, we chose not to ask the adolescents about their sexual orientation (heterosexuality, homosexuality or bisexuality), considering that it was too early for them to have made any final choice and that any homosexual or bisexual intercourse was likely to be a matter of experimentation. Further studies in young adults could determine whether sexual orientation influences the intention to use condoms.

\section{Conclusion and implications}

For the whole adolescent sample, the 'intention to use condoms' appears to be based on 'perceived control', 'individual attitudes' and 'subjective norms'. The results of this study suggest that the decision whether or not to use a condom during sexual encounters is strongly linked to 'perceived control' and to 'personal attitudes'. The best predictors of the intention to use condoms for girls are perceived control and individual attitudes, while individual attitudes 
is a better predictor than perceived control for boys. Thus, the 'intention to use a condom' depends more on personal, intimate factors (self-efficacy) for adolescent girls, while for boys the most decisive factors appear to be social and individual attitudes. The concept of selfefficacy in relation to condom use refers to factors such as confidence in the ability to buy condoms, to use them properly, or to suggest using one with a partner. Individual attitudes and perceived control are predictors of behaviour (condom use) for both boys and girls. This study also shows that the predictive power of the planned behaviour theory is different for boys and girls, the link between 'subjective socio-cultural norms' and intention being stronger for boys than for girls. From a practical point of view, these results can be used to develop preventive actions with regard to adolescents' use of condoms. For example, personal resources should be developed to overcome the psychological and physical obstacles linked to condom use, especially for girls. Sexual health programmes specifically targeted at girls should develop their skills (or ability), such as those needed for purchasing condoms, negotiating condom use, or even in the use of condoms. These skills can be developed through role play, feedback, imitation or training, with the aim of preparing individuals for action and encouraging adolescents to put their intentions into practice. It is also important to create favourable attitudes to condom use and to promote the support of family and peers. Professionals working with adolescents should be aware of the importance of the influence of parents and friends on the adolescents' behaviour. This factor must be taken into account in sex education programmes.

Declaration of interest: The authors report no conflicts of interest. The authors alone are responsible for the content and the writing of the paper. 


\section{REFERENCES}

1. Moreau C, Lydie N, Warszawski J, Bajos N. Activité sexuelle, IST, contraception : une situation stabilisée (Sexual activity, STIs, contraception: a stabilized situation). In: Guilbert P, Gautier A, eds. Baromètre santé 2005. Saint-Denis: INPES 2007:32955.

2. American Academy of Pediatrics. Committee on adolescence. Condom use by adolescents. Pediatrics 2001;107:1463-9.

3. Council of Ministers of Education. Canadian youth, sexual health and HIV/AIDS study: factors influencing knowledge, attitudes and behaviours. Ottawa: Canadian strategy on HIV/AIDS 2003.

4. Uzan M. Rapport sur la prévention et la prise en charge des grossesses des adolescentes (Report on the prevention and management of teenage pregnancies). Paris: Inserm 1998.

5. Panchaud C, Singh S, Feivelson D, et al. Sexually transmitted disease among adolescents in developed countries. Fam Plann Perspect 2000;32:32-45.

6. Ethier KA, Kershaw T, Niccolai L, et al. Adolescent women underestimate their susceptibility to sexually transmitted infections. Sex Transm Infect 2003;79:40811.

7. Bajos N, Bozon M, Beltzer N, Godelier M. Enquête sur la sexualité en France: pratiques, genre et santé (Survey on sexuality in France: practice, gender and health). Paris: La Découverte 2008.

8. Manlove J, Ikramullah E, Terry-Humen E. Condom use and consistency among male adolescents in the United States. J Adolesc Health Care 2008;43:325-33.

9. Ajzen I. Attitudes, personality, and behavior, $2^{\text {nd }}$ edn. Milton-Keynes, England: Open University Press 2005.

10. Ajzen I. The theory of planned behavior. Organ Behav Hum Decis Process 1991;50:179211.

11. Armitage CJ, Conner M. Efficacy of theory of planned behaviour: a meta-analytic review. Br J Soc Psychol 2001;40:471-99.

12. Albarracín D, Johnson BT, Fishbein M, Muellerleile PA. Theories of reasoned action and planned behaviour as models of condom use: a meta-analysis. Psychol Bull 2001;127:142-61.

13. Sheeran P, Taylor S. Predicting intentions to use condoms: a meta-analysis and comparison of the theories of reasoned action and planned behavior. J Appl Soc Psychol 1999;29:1624-75.

14. White KM, Terry DJ, Hogg MA. Safer sex behavior: the role of attitudes, norms and control factors. J Appl Soc Psychol 1994;24:2164-92.

15. Bosompra K. Determinants of condom use intentions of university students in Ghana: an application of theory of reasoned action. Soc Sci Med 2001;52:1057-69.

16. Posner SF, Salyers Bull S, et al. Factors associated with condom use among young Denver inner city women. Prev Med 2004;39:1227-33.

17. Wilson D, Zenda A, McMaster J, Lavelle S. Factors predicting Zimbabwean students' intentions to use condoms. Psychol Health 1992;7:99-114.

18. Godin G, Gagnon H, Lambert LD, Conner M. Determinants of condom use among a random sample of single heterosexual adults. Br J Health Psychol 2005;10:85100.

19. Gagné C, Godin G. Les théories sociales cognitives: guide pour la mesure des variables et le développement de questionnaire (Social cognitive theory: a guide for measuring variables and drawing up questionnaires). Québec: Université de Laval 
- Groupe de recherche sur les aspects psychosociaux de la santé. Ecole des sciences infirmières 1999:79.

20. Seal DW, Bloom FR, Somlai AM. Dilemmas in conducting qualitative sex research in applied field settings. Health Educ Behav 2000;27:10-23.

21. Goergen R. Cost effective and easy to handle methods for program design and evaluation in sexual and reproductive health programs for youths. Accessed 06 August 2011 from: http://www.ethiopia-ed.net/images/1743026877.doc

22. Escofier B, Pagès J. Analyses factorielles simples et multiples: objectifs, méthodes et interprétation (Single and multiple factorial analysis: goals, methods and interpretation). Paris: Dunod 1990.

23. Arbuckle JL. Amos 7.0 user's guide. Chicago, IL: SPSS 2006.

24. Roussel P, Durrieu F, Campoy E, El Akremi A. Méthodes d'équations structurelles: recherche et applications en gestion (Structural equation methods: research and management applications). Paris: Economica 2002.

25. Gredig D, Nideroest S, Parpan-Blaser A. HIV-protection through condom use: testing the theory of planned behaviour in a community sample of heterosexual men in a high-income country. Psychol Health 2006;21:541-55.

26. Jemmott JB, Heeren GA, Ngwane Z, et al. Theory of planned behaviour predictors of intention to use condoms among Xhosa adolescents in South Africa. AIDS Care 2007;19:677-84.

27. Muñoz-Silva A, Sánchez-García M, Nunes C, Martins A. Gender differences in condom use prediction with theory of reasoned action and planned behaviour: the role of self-efficacy and control. AIDS Care 2007;19:1177-81.

28. Craig DM, Wade KE, Allison KR, et al. Factors predictive of adolescents' intentions to use birth control pills, condoms, and birth control pills in combination with condoms. Can J Public Health 2000;91:361-5. 


\section{TABLES TO BE INSERTED IN THE TEXT}

Table 1: Results of the exploratory factorial analysis of items relative to condom use $(n=230)$

\begin{tabular}{|c|c|c|c|c|c|}
\hline & Factor & $\mathbf{I}$ & II & III & IV \\
\hline \multicolumn{6}{|c|}{$\mathrm{N}^{\circ}$ of items (loadings $>0.40$ ) } \\
\hline 19 & $\begin{array}{l}\text { It would be appropriate for a French person to use a condom } \\
\text { during every sexual encounter with a new partner }\end{array}$ & 0.75 & & & \\
\hline 18 & $\begin{array}{l}\text { It would be appropriate for a person of my gender to use a } \\
\text { condom during every sexual encounter. }\end{array}$ & 0.75 & & & \\
\hline 17 & $\begin{array}{l}\text { It would be appropriate for a person my age to use a condom } \\
\text { during each sexual encounter. }\end{array}$ & 0.68 & & & \\
\hline 03 & I would find using a condom: pleasant / unpleasant & & 0.71 & & \\
\hline 09 & I would find using a condom: easy / difficult & & 0.70 & & \\
\hline 01 & I would find using a condom: agreeable / disagreeable & & 0.59 & & \\
\hline 02 & I would find using a condom: useful / unhelpful & & 0.57 & 0.55 & \\
\hline 04 & I would find using a condom: careful / careless & & 0.55 & & \\
\hline 07 & $\begin{array}{l}\text { The people who are most important to me think that I should } \\
\text { use a condom. }\end{array}$ & & & 0.82 & \\
\hline 06 & $\begin{array}{l}\text { If I were to use a condom, the people who are most important } \\
\text { to me would: approve / disapprove }\end{array}$ & & & 0.81 & \\
\hline 08 & $\begin{array}{l}\text { The people who are most important to me think that it is right } \\
\text { to use a condom. }\end{array}$ & & & 0.78 & \\
\hline 05 & $\begin{array}{l}\text { The people who are most important to me think that I should } \\
\text { use a condom. }\end{array}$ & & & 0.70 & \\
\hline 15 & I would feel guilty if I did not use a condom & & & & 0.63 \\
\hline 13 & $\begin{array}{l}\text { I feel capable of using a condom during every sexual } \\
\text { encounter. }\end{array}$ & & & & 0.60 \\
\hline 12 & It is up to me to use a condom during each sexual encounter. & & & & 0.57 \\
\hline 16 & $\begin{array}{l}\text { I think that it would be morally acceptable not to use a } \\
\text { condom during the next three months. }\end{array}$ & & & & 0.57 \\
\hline 11 & $\begin{array}{l}\text { If I wished, I could easily use a condom during each sexual } \\
\text { encounter. }\end{array}$ & & & & 0.54 \\
\hline 14 & Using a condom is one of my principles. & 0.40 & & & 0.47 \\
\hline \multirow[t]{2}{*}{10} & $\begin{array}{l}\text { To what extent do you feel that you have control over using a } \\
\text { condom? }\end{array}$ & & & & 0.44 \\
\hline & Cronbach's alpha & 0.67 & 0.73 & 0.85 & 0.77 \\
\hline
\end{tabular}


Table 2: Correlations between individual attitudes, subjective norms, perceived control, intention to use and actual use of condoms by adolescents

\begin{tabular}{ccc}
\hline & $\begin{array}{c}\text { Intention to use } \\
\text { condoms } \\
(\mathrm{n}=230)\end{array}$ & $\begin{array}{c}\text { Condom use } \\
(\mathrm{n}=139)\end{array}$ \\
$\begin{array}{c}\text { Subjective norms } \\
\text { (sociocultural) }\end{array}$ & $0.29 * * *$ & $\mathrm{~ns}$ \\
$\begin{array}{c}\text { Subjective norms } \\
\text { (close friends and } \\
\text { relatives) }\end{array}$ & $0.29 * * *$ & $\mathrm{~ns}$ \\
$\begin{array}{c}\text { Individual attitudes } \\
\text { Perceived control }\end{array}$ & $0.26 * * *$ & $0.44 * * *$ \\
\hline \hline
\end{tabular}

ns: non-significant; *: $p<0.05 ; * *: p<0.01 ; * * *: p<0.001$. 
Table 3: Correlations between individual attitudes, subjective norms, perceived control, intention and actual condom use by adolescents according to gender

\begin{tabular}{|c|c|c|c|c|}
\hline & \multicolumn{2}{|c|}{$\begin{array}{l}\text { Intention to use } \\
\text { condoms }\end{array}$} & \multicolumn{2}{|c|}{ Condom use } \\
\hline & $\begin{array}{c}\text { Girls } \\
(\mathrm{n}=169)\end{array}$ & $\begin{array}{c}\text { Boys } \\
(\mathrm{n}=42)^{\mathrm{a}}\end{array}$ & $\begin{array}{c}\text { Girls } \\
(\mathrm{n}=102)\end{array}$ & $\begin{array}{l}\text { Boys } \\
(\mathrm{n}=23)\end{array}$ \\
\hline $\begin{array}{l}\text { Subjective norms } \\
\text { (sociocultural) }\end{array}$ & $0.27 * * *$ & $0.35^{*}$ & $\mathrm{~ns}$ & ns \\
\hline $\begin{array}{l}\text { Subjective norms } \\
\text { (close friends and } \\
\text { relatives) }\end{array}$ & $0.30 * * *$ & ns & $\mathrm{ns}$ & $\begin{array}{l}\text { ns }(0.40, \\
p=0.06)\end{array}$ \\
\hline Individual attitudes & $0.25 * * *$ & $0.39 *$ & $0.45 * * *$ & $0.64 * * *$ \\
\hline Perceived control & $0.43 * * *$ & $\mathrm{~ns}$ & $0.38 * * *$ & ns \\
\hline
\end{tabular}

a: 19 students $(8 \%)$ did not indicate their gender.

ns: non-significant; $*: p<0.05 ; * *: p<0.01 ; * * *: p<0.001$. 


\section{FIGURES TO BE INSERTED IN THE TEXT}

Figure 1: Ajzen's Theory of Planned Behaviour (TPB) ${ }^{9,10}$

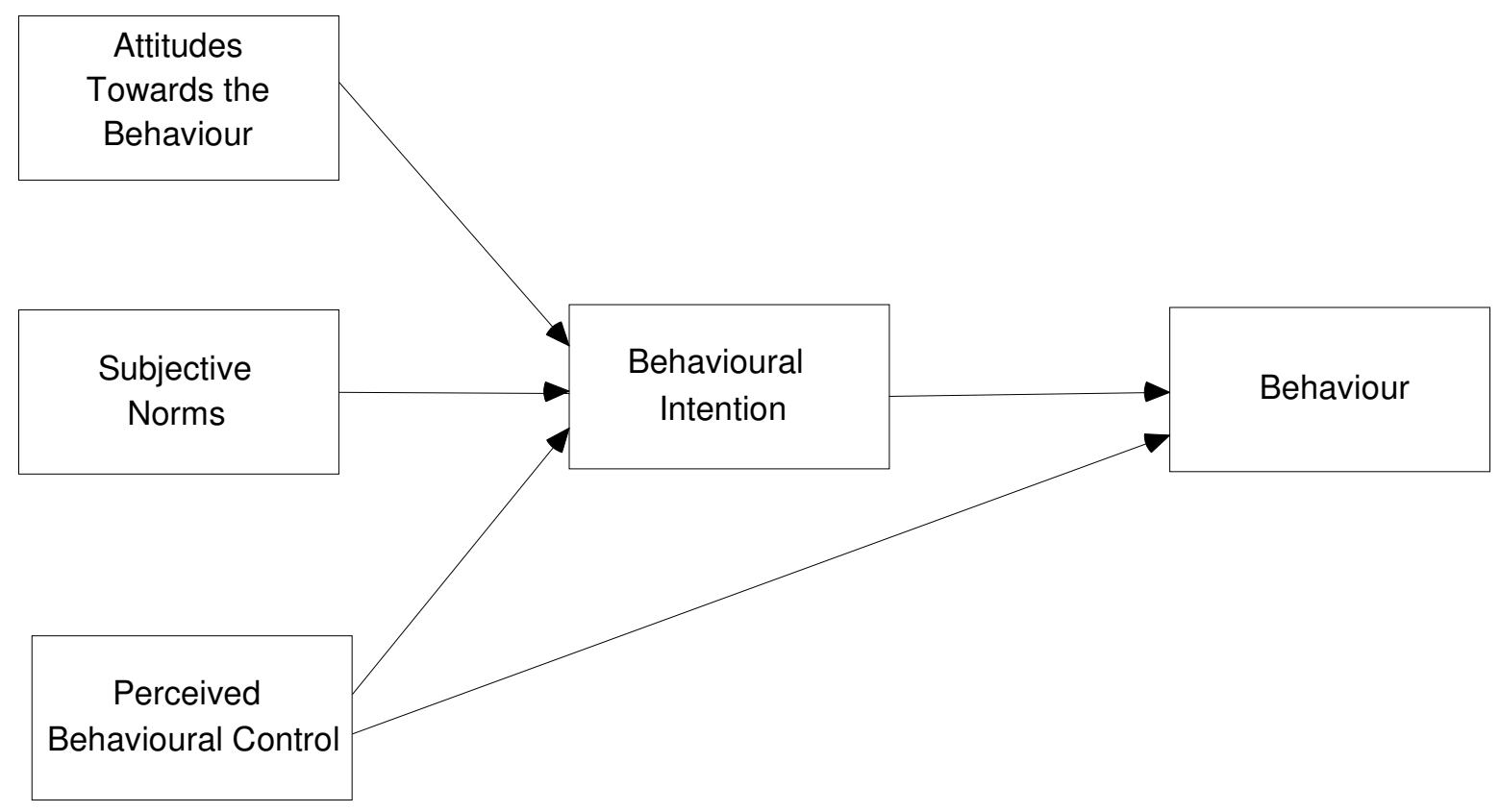


Figure 2: Analysis of relationships between individual attitudes, subjective norms, intention to use and actual use of condoms by adolescents $(n=139)$

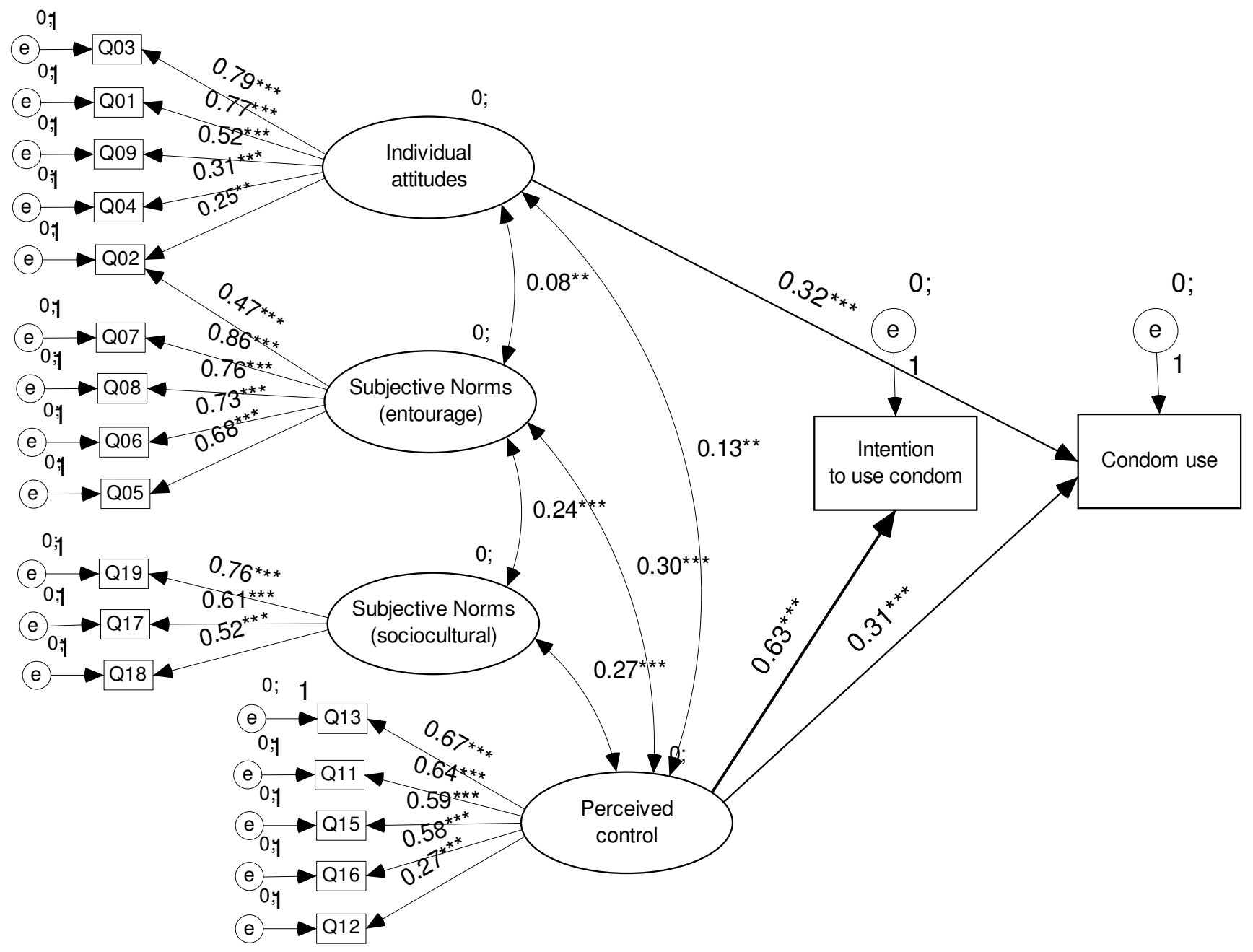

$* p<0.05 ; * * p<0.01 ; * * * p<0.001$.

$\chi^{2}=331.5$, df $($ degrees of freedom $)=145$

$\chi^{2}(\mathrm{CMIN}) / \mathrm{df}=2.29$

$p<0.0001$

CFI (Comparative fit index $)=0.86$

RMSEA (Root Mean Square Error of Approximation) $=0.07$ 